\title{
Research on Service Innovation of Financial Data based on Cloud Computing in Big Data Era
}

\author{
Ting Liu \\ Yichun Vocational Technology College, Yichun 336000, China \\ 20175490@qq.com
}

\begin{abstract}
With the increasing penetration of the Internet into people's lives, the financial market in the era of big data directly affects the asymmetric information mode between the supply and demand sides, and on this basis, it plays a positive role in guiding the subsequent optimization of financial market services, ensuring social fairness and reducing the exclusion of financial products. Big data finance under the Internet has narrowed the distance between supply and demand, subverted the problem of information asymmetry between the two sides, and injected new innovative means to alleviate financial exclusion, promote social equity and optimize financial services. In order to support the development of the real economy and enhance the core competitiveness of the industry, the process of data value chain has been continuously extended horizontally and vertically, but the data value chain of financial enterprises has been extended. In this paper, starting from the characteristics of the big data era, taking the carrier of value extension as the research goal, the big data value chain model of financial enterprises is constructed based on cloud computing technology, and the service innovation of China's financial data in the big data era is discussed.
\end{abstract}

Keywords: Cloud Computing; Big Data; Value Chain; Financial Market.

\section{Introduction}

With the rapid development of the Internet, big data focusing on information collection and data management has effectively changed the information asymmetry in the supply-demand relationship of the traditional financial industry and had a strong impact on the traditional financial industry [1]. In the current social context, big data finance is a hot issue and has impacted the traditional financial industry. Any economic and financial activity is a combined movement of information flow, material flow and financial flow [2]. Material flow is the basis and performance of real economic activities, while financial flow is the energy to promote material flow, which is the rights and interests of relevant subjects defined by money [3]. With the rapid development of the Internet, big data finance has become the focus of attention. Big data finance has changed the asymmetry between strong suppliers and weak demanders in traditional financial services. Big data finance in the Internet environment has narrowed the distance between supply and demand, overturned the problem of information asymmetry between the two sides, and injected new innovative means to alleviate financial exclusion, promote social equity and optimize financial services [4]. From the perspective of smart finance, the financial industry must provide customers with timely, convenient and safe financial services and financial information services [5]. Therefore, how to provide customers with timely, convenient and safe third-party electronic payment services through cloud computing technology, and how to provide investors with timely, comprehensive and reliable financial information services are issues of public concern.

With the increasing penetration of the Internet into public life, the financial market in the era of big data has directly affected the asymmetric information mode between the supplier and the demander. On this basis, it plays a positive guiding role in the subsequent optimization of financial market services, ensuring social fairness and reducing the exclusion of financial products [6]. In today's big data era, the core of the financial world is price transparency and its disintermediation. People usually adhere to the ideas and theories of sharing, cooperation, equality and openness, use big data technology efficiently, mine new financial net content in existing data assets, and provide customers with higher quality financial services [7]. From the analysis of the processing process of internal data assets of traditional financial enterprises, it can be seen that its process is a complete 
traditional data value chain, and the continuous cycle process from data generation to its value is through various system processing [8]. With the progress of human society and the continuous progress of science and technology, in order to support the development of real economy and enhance the core competitiveness of the industry, the process of data value chain has been continuously extended horizontally and vertically, but the extension of data value chain of financial enterprises [9]. Starting from the characteristics of the big data era, taking the value extension carrier as the research goal, this paper constructs the big data value chain model of financial enterprises based on cloud computing technology, and discusses the service innovation of China's financial data in the big data era.

\section{Characteristics of Financial Big Data}

\subsection{Large amount of Data and Single Structure}

Before the Internet became popular all over the world, the informatization construction of financial industry supported by traditional information technology was mainly based on the core production system, credit management system and various internal risk and performance management systems that provided services to customers in the enterprise LAN, to support the healthy and sustainable business development of enterprises. These data are backed up offline and operated online by the original and ancient methods, and stored through the national unified database. Only at that time, the financial data structure and storage mode were relatively simple. After the rapid development of the Internet, high-quality innovations such as e-banking and channels appeared in the financial industry, and the industry also achieved rapid growth, with the annual precipitation data increasing exponentially, which led to a huge amount of data in China's financial database. After the advent of the information age, the financial industry has a further innovation model based on it. Due to the multi-party cooperation among partners and efficient aggregation and sharing of resources in the business ecology brought by cloud computing technology, information is more transparent, services are more standardized in cooperation, and independent services will become more popular. Driven by the rapid development of Internet technology, financial service innovation has developed various high-quality service systems, including channels and e-banking, and the amount of data deposited every year has increased exponentially. At present, the financial industry is still a relatively closed loop, with structured data accounting for an absolute amount.

\subsection{The Relationship is Complex and Difficult to Sort out}

The dividend of rapid economic development is transmitted to all industries vertically and horizontally, and the financial industry is one of the most profitable industries. The scale of various financial institutions is growing rapidly, the types of business and products are constantly enriched, and the business lines are continuously lengthened. In order to support their development, the scale and types of financial enterprise information systems are constantly expanding and enriching. The financial industry has its own unique features. The data of various internal operating systems are closely coupled and have relatively complex connections. Especially, the initial comprehensive development of enterprises in the era of information construction should pay more attention to the inconsistency with the development goals of social information technology and services. With the rapid development of Internet technology, the types of service channels in the financial industry are constantly enriched, and the width and depth of channel services are constantly expanding, which forces the scale of informatization construction in the financial industry to be constantly expanded [10]. However, the financial industry has its particularity, and the relationships among the data of various internal management systems are strongly coupled, and the internal data flow is complicated. The financial industry has its own particularity, and all kinds of internal management system data are strongly coupled and complicated. In particular, the overall planning of enterprise information construction at the initial stage does not meet the development requirements of social information technology and services. 
In China, the big data technology is becoming more and more mature, and there is no technical bottleneck in the utilization of a large number of valuable data deposited in enterprises. At the same time, the innovation of service mode led by the Internet also provides many reference resources for promoting the horizontal and vertical extension of service channels in the financial industry. However, the key challenge is how to apply technology scientifically and reasonably to help clarify the relationship between data, improve data quality and give play to its value. With the rapid popularization of the Internet and the rapid development of big data financial technology theory, financial institutions that have experienced rapid development for decades are facing opportunities and challenges. Fortunately, in China, big data technology is becoming more and more mature, and many valuable data resources are not hindered by technology during the gradual accumulation within enterprises. At the same time, the innovation strategy of the Internet-led service model has promoted the depth and breadth of the financial service channels, which has great reference value. It is worth noting that the key challenge is how to use technology efficiently and standardly to clarify the relationship between data, improve the quality of resources and highlight their value, and pass on the value to realize secondary value-added.

\section{Big Data Value Chain Network of Financial Enterprises}

The so-called value network refers to all enterprises and personnel who have an interest relationship with financial enterprises, including employees, shareholders and service customers of financial enterprises, as well as various enterprises and personnel such as national financial industry regulatory agencies. These people form a value network through the interweaving of industrial chains. In the value network, every stakeholder is both an interest winner and a service provider. These stakeholders in different positions are connected through various channels which are beneficial for both parties to obtain and create value, and jointly create value for the society. In any aspect, all the factors closely related to the enterprise are intertwined by relying on the industrial value chain to form an exclusive value network. The various stakeholders mentioned here include: employees, shareholders and customers of financial enterprises, that is, those who need services and their related financial industry-oriented regulatory agencies. All stakeholders are in different positions in the unique value network of financial enterprises, and they are merged by means of obtaining qualifications and generating income. Each participant has obtained relevant services and contributed unique value to the society. Under the background of cloud computing, relying on information exchange and sharing on the Internet, material circulation on logistics network and capital exchange on financial network, commercial activities no longer depend on time and place. Business decisions can be made at any time and place depending on a terminal.

In the survival of the value network, mutual dependence is enhanced, and the individual is becoming a part of the whole and coexisting with the whole. The process of creating overall value by interdependence is also the process of enterprise's own value growth. This kind of cooperation is premised on mutual needs and common value growth. The business model of cloud computing based on value net is shown in Figure 1.

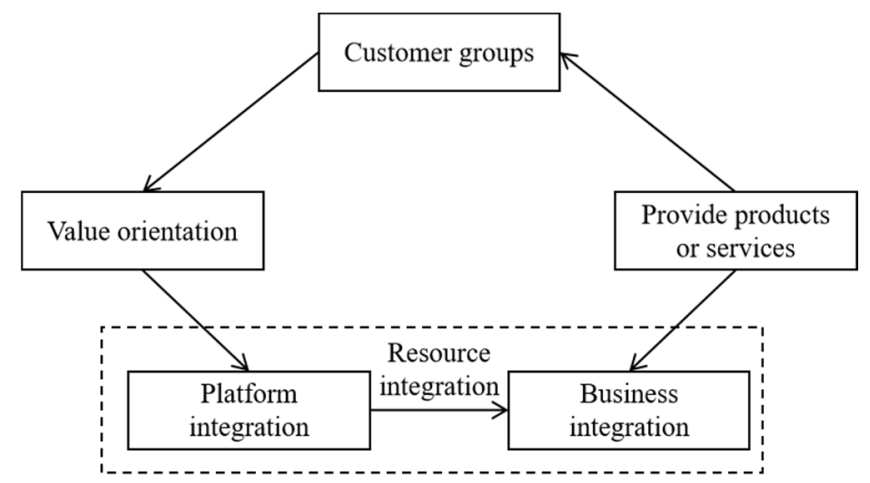

Figure 1. Cloud computing business model based on value network 
In the financial enterprise value network, the stakeholders in different positions in the network are combined together through various channels that are beneficial to both parties to create and obtain value, and jointly create value for the society. The tangible and intangible services that each participant receives are the manifestation of the ultimate value. Financial companies rely on valueadded data to enhance their core competitiveness, and obtain supplementary resources which are difficult to move and copy, rare and high in content, which are difficult for companies outside the value chain and value network to read. All stakeholders are in different positions in the value network of financial enterprises, and they are combined together through channels that can obtain value and create benefits, in which each participant has received services and created certain value for the society. Under the supervision and guidance of the national financial industry regulators, the financial managers lead their employees to focus on customers, provide high-quality and efficient services to customers, and create value for the society. The increasingly close interdependence of enterprises has become a feature of the network age. The economic activities of enterprises are increasingly dependent on other enterprises. The value chain formed by the enterprise's supply chain and sales chain depends more on its information chain and logistics chain, and becomes one of the value networks. Due to the professional technology of big data and the rapid development of multimedia, it is in the stage of in-depth use, which provides a certain technical guarantee for exploring and improving the value of resources, is conducive to the double-level improvement of data quality and efficiency, and improves the real experience of users. Relying on the theoretical research of value chain, its internal extensions can produce relevant values, thus enhancing the enterprise's capabilities and various data.

In the process of financial information processing, through the establishment of an effective combination of network technology and software technology, pay attention to the security policy of the financial system, and ensure the data security of financial enterprises. The data storage security architecture of cloud computing is shown in Figure 2.

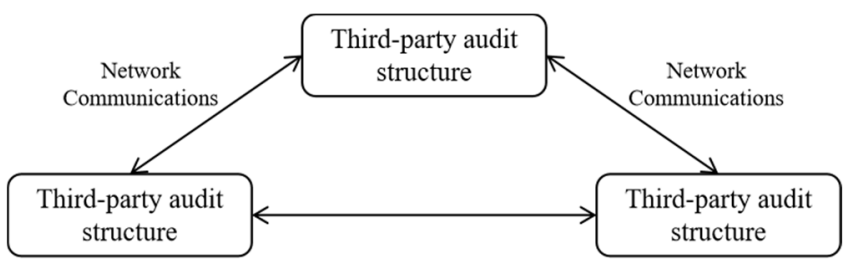

Figure 2. Cloud computing data storage security architecture

The main responsibility of the national financial industry regulatory agency is to supervise and guide, to ensure that financial enterprises can play their core role for national economic development, and the guidance of macro-economic development and financial industry planning policies can provide value-added foundation and strategic development direction for financial enterprises' innovative services. Financial shareholders are the managers of financial enterprises, and according to the provisions of laws and regulations, they can ensure the stable and sustainable operation of enterprises and create both financial value and intangible value for themselves and enterprises. For financial enterprises, data is the core factor of production, and enterprises should be guided by the theory of value chain model to maximize the interests of all stakeholders in the value network, which requires financial enterprises to establish relevant platforms for value transmission and acquisition. Financial enterprises can enhance their core competitiveness through data appreciation, and can obtain complementary resources which are difficult to move, difficult to imitate, scarce and highvalue that are not easy for enterprises outside the value chain and value network. The value-added space and methods of traditional data value chain are easily restricted. However, with the rapid development of big data technology and the Internet, advanced and effective technology and theoretical guidance have been brought for the in-depth utilization, mining and promotion of data value, which has improved the quality and efficiency of data value utilization, enhanced the actual experience of users and maintained the strategic assets necessary for enterprise innovation. 


\section{Conclusion}

Data is the core production factor of financial enterprises, and data value chain is the nerve of economic activities of financial enterprises. The financial big data market is based on the analysis and construction of data within the enterprise, to provide customers with the relevant services they need. Here, it can not only analyze customers' thoughts through big data at all times, but also specify the products of data in a personalized way, and assist the senior management of its company to better complete the internal control of the enterprise and better serve its customers for related operations. Enterprises can create benefits by controlling and managing the data flow, construct the enterprise financial value chain network according to the value chain theory, and divide all stakeholders in the network. Cloud computing provides technology for early warning and monitoring of risks in the era of big data, so that systematic risks can be found in time and control measures can be taken. Cloud computing provides technical guarantee for process operation, which can strengthen cooperation with external based on real-time internal and external information, and strengthen risk management in the process. With the deepening of financial innovation, there are more ways to generate systemic risks. Preventing and controlling systematic risks in the era of financial innovation has become a new problem that must be overcome.

\section{References}

[1] Zhang Jing, Wei Shuang. Financial data service innovation analysis under big data[J]. Digital Technology and Application, 2018, 332(02):218-219.

[2] Yu Kai, Tang Luping. Big data technology helps financial service industry[J]. Information Recording Materials, 2018, 019(001):65-67.

[3] Wang Yihan. Discussion on Internet Finance Innovation in the Big Data Era[J]. Times Finance, 2018, 687 (05):41+44.

[4] Lu Minfeng, Ge Heping. Research on the Appropriate Balance of Fintech Innovation and Fintech Supervision [J]. Rural Finance Research, 2017, 09(450):9-14.

[5] Research Group of Nanjing Rural Finance Society, Liu Zhengru. Financial Technology Innovation and Reconstruction of Banking Business Model[J]. Modern Finance, 2019, 433(03):34-36.

[6] He Liyan. Analysis of Internet Financial Innovation Strategy in the Big Data Era[J]. Think Tank Times, 2020, 226(06):51-52.

[7] Feng Juan, Yuan Chunfen. Research on Innovation of Supply Chain Financial Risk Management in the Context of Big Data[J]. Shangxun, 2019, 187(33):88-89.

[8] An Qian. Innovative construction of financial engineering specialty based on the background of smart finance[J]. Educational Observation, 2019, 219(35):65-67.

[9] He Yongchuan, Liu Yalan, Ao Yixuan, et al. Research on the Influencing Factors of Financial Service Innovation Decisions in the Big Data Era [J]. Frontiers of Social Sciences, 2019, 008(004):548-555.

[10] Liu Xiaohua. Research on Internet Finance Innovation in the Era of Big Data[J]. Financial Technology Era, 2020, 301(09):100-102. 